\title{
Practical Applications of Scanning Electron Microscopy in a Public School
}

\author{
Kara Curry*, Kassandra Reed*, Mikayla Sonneborn*, Lurea Doody**, Gary Casuccio*** \\ * Student research group, West Greene High School, Waynesburg, PA 15370 \\ **West Greene High School, Chemistry, Waynesburg, PA 15370 \\ ***RJ Lee Group, Inc., Monroeville, PA 15416
}

Catalytic synthesis of cyanoacrylate nanofibers is just one of the research projects students at a small rural Pennsylvania high school have been working on this year. Every school has the capability to synthesize nanofibers, but most do not have access to the sophisticated technology needed to examine the results. West Greene is the only high school in the United States that owns a scanning electron microscope (SEM) dedicated to student use. Scanning electron microscopy was introduced to the school by RJ Lee Group, Inc. in 1997 as part of the Schoolhouse Project [1]. This project sought to "provide exceptional educational and business opportunities to its students." The program's main goal was "motivating students to pursue advanced education in math, computer science, engineering, and basic science while enriching educational experiences beyond what is commonly available to students in rural communities." In 2000, the microscope was purchased with a grant awarded by the Appalachian Regional Commission (ARC). Currently, the SEM laboratory is used in nanotechnology, chemistry, biology, and physics classes, and for science based senior projects. Most students complete an individual research project on the SEM before they graduate as part of their graduation requirement in chemistry.

Nanotechnology initiatives are evident in professional science organizations, universities and schools. In response to this call, students who complete the basic SEM course are now offered a course in nanotechnology. Students enrolled in this premier course are building their own base of research for the synthesis of nanoparticles and nanofibers. The students use experiments found in the literature as an outline for designing their own procedures that fit into the experimental limitations of a public high school. Because many of the experiments are unsuccessful, students engage in the analysis and modification of the 'failed' experiments based on their results.

One experiment chosen by the group was the fabrication of nanofibers on a fingerprint using the super glue fuming technique. Students used research from a paper entitled "Facile Catalytic Growth of Cyanoacrylate Nanofibers" [2]. They tried several combinations of real versus 'fake' fingerprints. The real fingerprints yielded no discernable results. The fake fingerprints were made using linoleic acid from evening primrose oil and dilute sodium hydroxide solution. After several attempts and adjustments to sodium hydroxide concentrations and chamber humidity, the group finally got a product which was unlike any they were expecting. Instead of a garden of fibers, they grew what appeared to be nano-stars [Fig. 1]. Other experiments the group is researching include making edible donut shaped nanoparticles from cyclodextrin and "green" nanoparticle synthesis of gold using sodium tetrachloroaurate, black tea, and soybeans. In addition, the group mentors and collaborates with their peers from other courses in how to use the SEM for projects in biology and physics. The types of projects and experiments that have been done are as dynamic and diverse as the personalities of the students. Other activities centered around the SEM lab include: A local 'Ugly Bug' competition [Fig. 2], Pennsylvania Junior Academy of Science projects, and demonstrations for middle school science students. 


\section{References:}

[1] The Schoolhouse Project; ARC Contract \#PA-13678

[2] "Facile catalytic growth of cyanoacrylate nanofibers" Pratik J. Mankidy, Ramakrishnan Rajagopalan and Henry C. Foley* (Chem. Commun., 2006, Issue 10, p. 1139 - 1141).

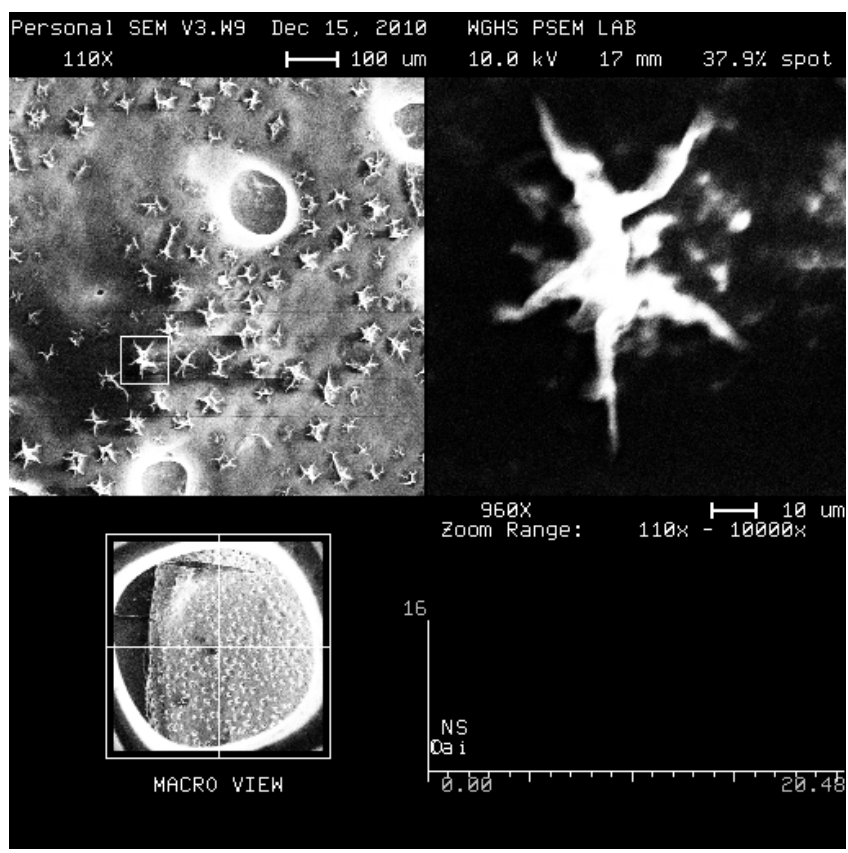

Fig. 1: Nanostars synthesized using fingerprints and cyanoacrylate fuming.

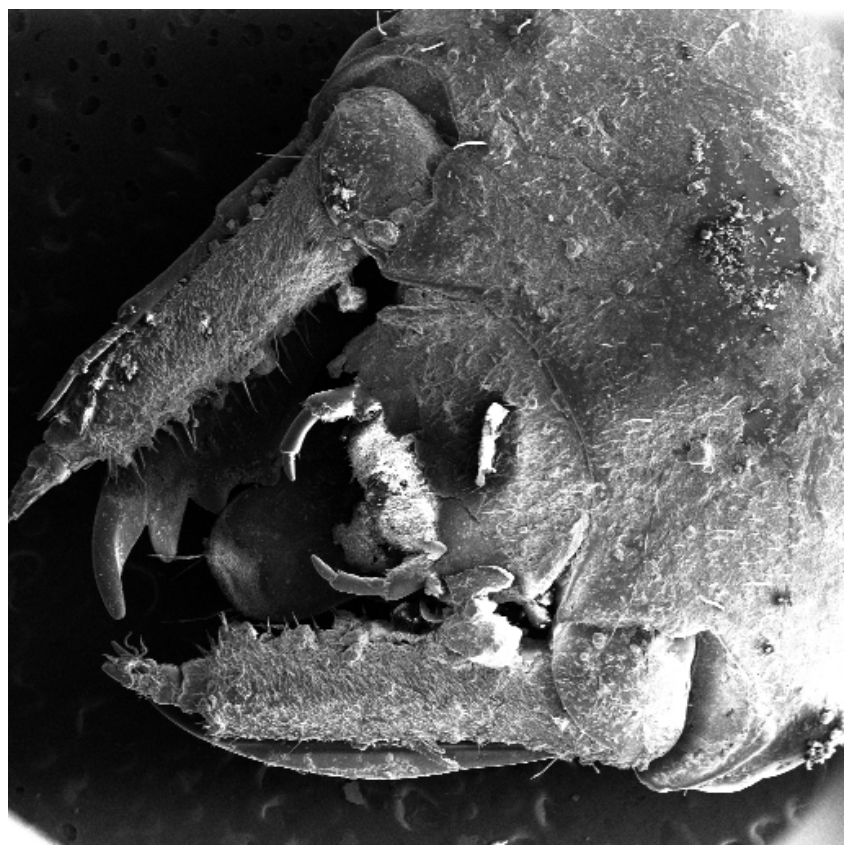

Fig. 2: Helgramite, 2010 winner West Greene Ugly Bug Pageant. 